Research Article

\title{
Evaluation of prescribing patterns of teaching and non teaching hospitals by undergraduate medical students in Pune, India
}

\author{
Anjali Pillay, Yogendra Keche*, Radha Yegnanarayan, Vaibhav Patil, \\ Gargi Patil, Renuka Dangare
}

Department of Pharmacology, Smt. Kashibai Navale Medical College and Hospital, Narhe Ambegaon, Pune-411041, India

Received: 21 November 2012

Revised: 12 December 2012

Accepted: 13 December 2012

*Correspondence to:

Dr. Yogendra Keche,

Email: drynkeche@gmail.com

\begin{abstract}
Background: This study was carried out in various hospitals to analyze the use of rational fixed dose combinations (FDCs) in Pune.

Methods: 279 prescriptions were evaluated in this study. Information about age, sex, names of the all the drugs prescribed by doctor/ physician, diagnosis for the use of prescriptions and adverse effects were noted in the audit form from the prescriptions of the patients. Rationality of fixed dose combination is evaluated according to WHO Model List of Essential Drugs, 17th updated version, 2011.
\end{abstract}

Results: $56.98 \%$ doctor's prescriptions in this study were containing of fixed dose combinations and out of this $10.69 \%$ prescriptions were including two or more FDCs in their prescriptions. Only $13.20 \%$ FDCs were in accordance with WHO Model List of Essential Drugs. FDCs from antiinflammatory and antirheumatic products, vitamins, minerals, antianaemic preparations, drugs for acid related disorders, antibacterials for systemic use and cough and cold preparations were used more by private non teaching hospitals as compared to SKNMC \& GH teaching hospital. $64.61 \%$ prescriptions of private hospitals and $34.08 \%$ prescriptions of teaching hospital were containing more than one drug.

Conclusions: This study has shown that about every alternate prescription contains FDC. More than $80 \%$ of prescribed FDCs are not in accordance with Essential Drugs List. Vitamins, minerals, antianaemic preparation FDCs should be prescribed judiciously as they are not free from ADRs. More number of drugs (poly-pharmacy) and FDCs were prescribed by non teaching private hospitals.

Keywords: FDCs, prescription analysis, rational use of drugs

\section{INTRODUCTION}

A fixed dose combination (FDC) refers to the combination of two or more drugs in a single formulation. Irrational drug prescribing of FDCs is common clinical practice. Important reasons for irrational prescribing are poor knowledge about the drugs and unethical drug promotion by pharmaceutical companies. ${ }^{1}$

There is tremendous increase in pharmaceutical products in the market for protecting, restoring and maintaining health which also leads to increased cost of healthcare. In developing countries like India, there are limited economic resources and lack of organised drug policies; these again increase burden of costs of drugs to the patients. For optimal use of drugs, WHO in 1977 published 1st List of Essential Drugs. Optimal use of drugs means use of therapeutically proven effective, safe, suitable drugs and satisfying the health needs of population. $^{2}$

More than $80 \%$ of prescribed FDCs are not according to WHO Model Essential Drug List. ${ }^{3}$ WHO Model List of Essential Drugs 17th edition ( March 2011) includes only 24 FDCs. ${ }^{4}$ Unnecessary drug and money of patient is being wasted and patient is being exposed to ADRs of additional drug in FDCs. 
Kshirsagar et $\mathrm{al}^{2}$ in 1998 observed that around 55\% prescribed drugs by practitioners in Pune were in the form of FDCs and $64 \%$ prescribed FDCs were found to be being used unnecessarily. Shewade et al. ${ }^{1}$ observed that teaching hospital physicians were prescribing more rational prescriptions.

Rational drugs policy or an essential drugs list will be useless unless accompanied by intensive efforts to improve the education and updating of doctors and pharmacists and to reduce the commercial pressures on doctors to prescribe unnecessary drugs. There are various revisions in WHO model essential drug list and newer drug combinations introduced. There is need for carry out prescriptions monitoring in hospitals as well as of private practitioners. Therefore, this study was planned to study the rational use of FDCs by analyzing the prescriptions issued by doctors in Pune.

\section{Aims and objectives}

1. To find out most commonly used FDCs in Pune.

2. To find out groups of drugs from which FDCs are prescribed.

3. To find the FDCs to which patients report ADRs.

4. To compare the prescription patterns between Smt. Kashibai Navale Medical College and General Hospital (SKNMC \& GH) teaching hospital and other private non teaching hospitals.

\section{METHODS}

\section{Study site}

The data for this study was collected by II MBBS students of Smt. Kashibai Navale Medical College and Hospital, Narhe Ambegaon, Pune, Maharashtra, India by: 1) visiting various OPDs counters of Smt. Kashibai Navale Medical College like surgery, medicine, ENT, dermatology, orthopedics, gynecology and collecting data from prescriptions of patients (teaching hospital). 2) prescriptions of private hospitals at medical shops or from private hospitals in Pune from Narhe, Dhayari, Bhavani Peth, Kothrud and Pimpri Chinchwad areas of Pune City (non teaching hospital). Permission from the private hospitals administration was taken for collecting the data by the students.

\section{Study design and sampling}

It was a cross sectional observational study. The data was collected over 9 months by II MBBS students.

\section{Study tools}

Total prescriptions were 279, out of which 132 were collected from teaching hospital and 147 were collected from non teaching private hospitals. Data was collected in semi-structured questionnaire format prepared by Department of Pharmacology, SKNMC \& GH. Information about the drugs prescribed by the doctors, ingredients in drug combination, duration of therapy, frequency of drug administration, diagnosis for the drug use, ADRs to FDCs reported by patients was collected from prescriptions. Literature data $^{5}$, time course of appearance of adverse effects and period of drug administration was used for assigning the ADR to particular FDCs. The information obtained by the students has been audited for rationality of FDCs with the help of WHO Essential Drug list, 17th edition (March 2011). ${ }^{4}$

\section{Statistical analysis}

As there is absence of substantial data for prescription audit, we had taken approximately 300 prescriptions as sample size, out of which, for 279 prescriptions, we had complete information. Hence we carried out analysis of 279 prescriptions. Data was expressed as number or percentages of FDCs or drugs prescribed by doctors. Proportion of different FDCs or drugs prescribed by doctors was found out and comparison was done between the different drug groups. Chi-square test was used for comparison of prescriptions of SKNMC \& GH and nonteaching private hospitals.

\section{RESULTS}

Demographic characteristics are comparable in both the groups (Table 1). 24.63\% of FDCs in SKNMC teaching hospital and $15.55 \%$ of FDCs in non teaching private hospitals were in accordance with the WHO recommended list of FDCs. Significantly less number of FDCs and more rational FDCs had been prescribed by SKNMC \& GH teaching hospital (Table 2).

Table 1: Demographic characteristics of the study population.

\begin{tabular}{|lll|}
\hline & \multicolumn{2}{l|}{ No. $(\%)$ of prescriptions } \\
\hline $\begin{array}{l}\text { Demographic } \\
\text { character }\end{array}$ & $\begin{array}{l}\text { SKN teaching } \\
\text { hospital }\end{array}$ & $\begin{array}{l}\text { Private } \\
\text { nonteaching } \\
\text { hospitals }\end{array}$ \\
\hline $\begin{array}{l}\text { Total prescriptions } \\
\text { Sex } \text { : Male }\end{array}$ & 132 & 147 \\
\multicolumn{1}{|c|}{ Female } & $62(46.97)$ & $86(58.50)$ \\
\hline $\begin{array}{l}\text { Age-wise } \\
\text { distribution of } \\
\text { prescriptions }\end{array}$ & $70(53.03)$ & $61(41.50)$ \\
$\begin{array}{l}\text { 0-15 yrs } \\
\text { 16-30 yrs }\end{array}$ & $17(12.88)$ & $12(8.16)$ \\
$\begin{array}{l}\text { 31-45 yrs } \\
\text { 46-60 yrs }\end{array}$ & $56(42.42)$ & $60(40.82)$ \\
61- 75 yrs & $23(17.42)$ & $42(28.57)$ \\
$>75$ yrs & $18(13.64)$ & $23(15.65)$ \\
\hline
\end{tabular}


Table 2: Comparison of prescriptions of teaching and non teaching hospitals.

\begin{tabular}{|c|c|c|c|}
\hline Parameters & $\begin{array}{l}\text { SKNMC \& GH } \\
\text { teaching hospital } \\
- \text { No. }(\%)\end{array}$ & $\begin{array}{l}\text { Private non teaching } \\
\text { hospitals - No. }(\%)\end{array}$ & $p$ value \\
\hline Total Prescription & 132 & 147 & \\
\hline FDCs prescribed & $69(52.27)$ & $90(61.22)$ & 0.25 \\
\hline $\begin{array}{l}2 \text { or more FDCs per } \\
\text { prescription }\end{array}$ & $6(4.55)$ & $11(7.48)$ & 0.63 \\
\hline Rational FDCs & $28(40.58)$ & $22(24.44)$ & 0.03 \\
\hline $\begin{array}{l}\text { FDCs included in WHO } \\
\text { essential drug list }\end{array}$ & $17(24.64)$ & $14(15.56)$ & 0.15 \\
\hline No. $(\%)$ of drugs/ prescription & & & \\
\hline One drug/ prescription & $87(65.90)$ & $52(35.37)$ & 0.00003 \\
\hline 2 drugs / prescription & $18(13.64)$ & $22(14.97)$ & 0.99 \\
\hline$>2$ drugs / prescription & $27(20.46)$ & $73(49.66)$ & 0.00002 \\
\hline
\end{tabular}

FDCs from antiinflammatory and antirheumatic products, vitamins, minerals, antianaemic preparations, drugs for acid related disorders, antibacterials for systemic use and cough and cold preparations were used more by private non teaching hospitals as compared to SKNMC teaching hospital. FDCs from antiinflammatory and antirheumatic products, vitamins, drugs for acid related disorders are widely prescribed irrational FDCs not having any rational basis (Table 3).

Adverse effects were reported by patients who were coming for refilling of prescriptions. Analgesics FDCs caused more number of ADRs amongst all prescribed FDCs (Table 4). No serious ADRs were reported in this study.

Table 5 shows different FDCs with Anatomical Therapeutic Classification (ATC) class prescribed by physicians in Pune. Ibuprofen + paracetamol, pantoprazole + domperidone, calcium + vitamin D3, ciprofloxacin + tinidazole are notable examples of commonly prescribed FDCs in Pune.

Table 3: Different drug groups of FDCs as WHO ATC class prescribed by teaching and non teaching hospitals.

\begin{tabular}{|c|c|c|c|c|c|}
\hline \multirow{2}{*}{\multicolumn{2}{|c|}{ Drug Groups of FDCs }} & \multicolumn{2}{|c|}{ No. $(\%)$ FDC prescribed } & \multicolumn{2}{|c|}{$\begin{array}{l}\text { No. }(\%) \text { Rational FDCs } \\
\text { prescribed }\end{array}$} \\
\hline & & \multirow{2}{*}{ 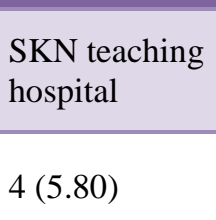 } & \multirow{2}{*}{ 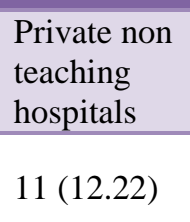 } & \multirow{2}{*}{$\begin{array}{l}\text { SKN teaching } \\
\text { hospital } \\
0\end{array}$} & \multirow{2}{*}{ 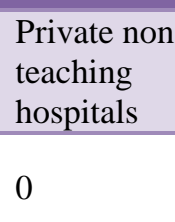 } \\
\hline 1 & A 02-Drugs for acid related disorder & & & & \\
\hline 2 & $\begin{array}{l}\text { A 03- Drugs for functional } \\
\text { gastrointestinal disorder }\end{array}$ & $4(5.80)$ & $4(4.44)$ & 0 & 0 \\
\hline 3 & $\begin{array}{l}\text { A 07- Antidiarrheals, intestinal anti- } \\
\text { inflammatory /antiinfective agents }\end{array}$ & $1(1.45)$ & $1(1.11)$ & $1(1.45)$ & $1(1.11)$ \\
\hline 4 & A 10- Drugs used in diabetes & $2(2.89)$ & $1(1.11)$ & 0 & 0 \\
\hline 5 & A 11- Vitamins & $4(5.80)$ & $10(12.22)$ & 0 & 0 \\
\hline
\end{tabular}




\begin{tabular}{|c|c|c|c|c|c|}
\hline 6 & A 12- Mineral supplements & $16(23.19)$ & $10(12.22)$ & $16(23.19)$ & $10(11.11)$ \\
\hline 7 & B 01- Antithrombotic agents & 0 & $1(1.11)$ & 0 & 0 \\
\hline 8 & B 03- Antianaemic preparations & $7(10.14)$ & $6(6.67)$ & $7(10.14)$ & $6(6.67)$ \\
\hline 9 & $\begin{array}{l}\text { D 01- Antifungals for dermatological } \\
\text { use }\end{array}$ & 0 & $1(1.11)$ & 0 & 0 \\
\hline 10 & D 02- Emollients and protectives & 0 & $1(1.11)$ & 0 & 0 \\
\hline 11 & $\begin{array}{l}\text { D 07- Corticosteroids and } \\
\text { dermatological preparations }\end{array}$ & 0 & $1(1.11)$ & 0 & 0 \\
\hline 12 & D 10- Anti-acne preparations & $4(5.80)$ & 0 & 0 & 0 \\
\hline 13 & J 01- Antibacterials for systemic use & $5(7.25)$ & $9(10)$ & $4(5.80)$ & $4(4.44)$ \\
\hline 14 & J 04- Antimycobacterials & 0 & $1(1.11)$ & 0 & 0 \\
\hline 15 & $\begin{array}{l}\text { M 01- Antiinflammatory and } \\
\text { antirheumatic products }\end{array}$ & $5(7.25)$ & $18(20)$ & 0 & 0 \\
\hline 16 & M 03- Muscle relaxants & 0 & $1(1.11)$ & 0 & 0 \\
\hline 17 & N 04- Anti-Parkinson's drugs & 0 & $1(1.11)$ & 0 & $1(1.11)$ \\
\hline 18 & N 05- Psycholeptics & $1(1.45)$ & $1(1.11)$ & 0 & 0 \\
\hline 19 & R 01- Nasal preparations & $1(1.45)$ & $1(1.11)$ & 0 & 0 \\
\hline 20 & $\begin{array}{l}\mathrm{R} 03 \text { - Drugs for obstructive airway } \\
\text { disease }\end{array}$ & $8(11.59)$ & $6(6.67)$ & 0 & 0 \\
\hline \multirow[t]{2}{*}{21} & R 05- Cough and cold preparations & $7(10.14)$ & $5(5.56)$ & 0 & 0 \\
\hline & & 69 (100) & $90(100)$ & $28(40.58)$ & $22(24.44)$ \\
\hline
\end{tabular}

Table 4: Adverse drug reactions (ADRs) reported by patients and found to be associated with FDCs.

\begin{tabular}{|llll|}
\hline Groups of drug & Name of FDCs causing ADRs & Adverse effects & $\begin{array}{l}\text { No. of patients } \\
\text { reported }\end{array}$ \\
\hline $\begin{array}{l}\text { M01- anti- } \\
\text { inflammatory } \\
\text { and } \\
\text { antirheumatic } \\
\text { products }\end{array}$ & $\begin{array}{l}\text { Ibuprofen + Paracetamol } \\
\text { Diclofenac + Paracetamol } \\
\text { Aceclofenac + Paracetamol } \\
\text { Nimesulide + Paracetamol }\end{array}$ & $\begin{array}{l}\text { Hyperacidity, loss of appetite, } \\
\text { dizziness, nausea, vomiting, sour } \\
\text { taste }\end{array}$ & 8 \\
\hline $\begin{array}{l}\text { J01 - } \\
\text { Antibacterials } \\
\text { for systemic use }\end{array}$ & $\begin{array}{l}\text { Amoxicillin + Clavulanic acid } \\
\text { Piperacillin + Tazobactam }\end{array}$ & $\begin{array}{l}\text { Diarrhea, vomiting, nausea, } \\
\text { hypoglycemia }\end{array}$ & 3 \\
$\begin{array}{l}\text { A02- drugs for } \\
\text { acid related } \\
\text { disorder }\end{array}$ & $\begin{array}{l}\text { Pantoprazole + Domperidone } \\
\text { Aluminium hydroxide + Magnesium } \\
\text { trisilicate liquid + Dimethicon }\end{array}$ & $\begin{array}{l}\text { Loss of appetite, giddiness, } \\
\text { headache, muscle cramps, sedation, } \\
\text { headache, loose stools } \\
\text { Nausea }\end{array}$ & 4 \\
\hline
\end{tabular}


A11-Vitamins

A12-mineral supplements

B03-

antianaemia

preparations

N05-

psycholeptics

R05- cough and

cold

preparations
Vitamin B complex

Multivitamin and minerals

Calcium + Vitamin D

Iron + Folic acid
Headache, constipation, epigastic

pain, nausea, vomiting, metallic taste

FDCs- Fixed dose combinations

Table 5: Different FDCs prescribed by physicians in Pune with WHO ATC class and code.

\begin{tabular}{|c|c|c|c|c|}
\hline Sr. No. & Name of FDCs prescribed by doctors & $\begin{array}{l}\text { ATC } \\
\text { code of } \\
\text { drug }\end{array}$ & $\begin{array}{l}\text { Private non } \\
\text { teaching } \\
\text { hospitals }\end{array}$ & $\begin{array}{l}\text { SKN } \\
\text { teaching } \\
\text { hospital }\end{array}$ \\
\hline \multicolumn{5}{|c|}{ A 02-Drugs for acid related disorder } \\
\hline 1 & Pantoprazole + Domperidone & A02BX & 9 & 3 \\
\hline 2 & Alum. Hydrox. + Mag.Trisil. + Dimethicon & A02AD02 & 2 & 1 \\
\hline \multicolumn{5}{|c|}{ A 03- Drugs for functional gastrointestinal disorder } \\
\hline 3 & Mefenamic acid + Dicyclomine & A03DB04 & 4 & 4 \\
\hline \multicolumn{5}{|c|}{ A 07- Antidiarrheals, intestinal anti-inflammatory/antiinfective agents } \\
\hline 4 & Diphenoxylate+ Atropine & $\begin{array}{ll}\text { A07DA02 } & 15 \mathrm{mg} \text { (ref to } \\
& \text { Diphenoxylate) }\end{array}$ & 1 & 1 \\
\hline \multicolumn{5}{|c|}{ A 10- Drugs used in diabetes } \\
\hline 5 & Glimepiride + Metformin & A10BD02 & 1 & 1 \\
\hline 6 & Pioglitazone + Glimepiride & A10BD06 & 0 & 1 \\
\hline \multicolumn{5}{|c|}{ A 11- Vitamins } \\
\hline 7 & Vitamin B Complex & A11EA & 4 & 2 \\
\hline 8 & Minerals + vitamins & A11JB & 6 & 2 \\
\hline \multicolumn{5}{|c|}{ A 12- Mineral supplements } \\
\hline 9 & Oral Rehydration Salt solution (ORS) & $\mathrm{A} 12 \mathrm{C}$ & 5 & 8 \\
\hline 10 & calcium + VitD3 & A12AX & 5 & 8 \\
\hline \multicolumn{5}{|c|}{ B 01- Antithrombotic agents } \\
\hline 11 & Clopidogrel + Aspirin & $\mathrm{B} 01 \mathrm{AC} 30$ & 1 & 0 \\
\hline \multicolumn{5}{|c|}{ B 03- Antianaemic preparations } \\
\hline 12 & Iron + folic acid & B03AD03 & 6 & 7 \\
\hline \multicolumn{5}{|c|}{ D 01- Antifungals for dermatological use } \\
\hline 13 & Clobetasol + Neomycin + Miconazole & D01AC20 & 1 & 0 \\
\hline \multicolumn{5}{|c|}{ D 02- Emollients and protectives } \\
\hline 14 & Aloe vera + Calamine cream & D02B & 1 & 0 \\
\hline \multicolumn{5}{|c|}{ D 07- Corticosteroids and dermatological preparations } \\
\hline 15 & Mometasone furoate + Salicylic acid & D07XC03 & 1 & 0 \\
\hline \multicolumn{5}{|c|}{ D 10-Anti-acne preparations } \\
\hline
\end{tabular}




\begin{tabular}{|c|c|c|c|c|c|}
\hline 16 & Adapalene + Clindamycin & D10AD53 & & 0 & 4 \\
\hline \multicolumn{6}{|c|}{ J 01- Antibacterials for systemic use } \\
\hline 17 & Amoxycillin + Clavulanic acid & J01CR02 & $\begin{array}{l}1 \mathrm{gm}(\mathrm{ref} \\
\text { amoxicillin) }\end{array}$ & 1 & 2 \\
\hline 18 & Ceftriaxone + Sulbactam & J01CG02 & & 1 & 1 \\
\hline 19 & Cefoperazone + Sulbactam & J01CG02 & & 1 & 0 \\
\hline 20 & Piperacillin + Tazobactam & J01CG02 & & 1 & 1 \\
\hline 21 & Ciprofloxacin + Tinidazole & J01R & & 2 & 0 \\
\hline 22 & Ofloxacin + Ornidazole & J01R & & 3 & 1 \\
\hline \multicolumn{6}{|c|}{ J 04- Antimycobacterials } \\
\hline 23 & Rifampicin + Isoniazid & J04AM02 & & 1 & 0 \\
\hline \multicolumn{6}{|c|}{ M 01- Antiinflammatory and antirheumatic products } \\
\hline 24 & Mefenamic acid + Paracetamol & M01BX & & 2 & 0 \\
\hline 25 & Aceclofenac + Paracetamol & M01BX & & 2 & 1 \\
\hline 26 & Diclofenac + Paracetamol & M01BX & & 4 & 2 \\
\hline 27 & Nimesulide + Paracetamol & M01BX & & 0 & 1 \\
\hline 28 & Ibuprofen + Paracetamol & M01AE51 & & 10 & 1 \\
\hline \multicolumn{6}{|c|}{ M 03-Muscle relaxants } \\
\hline 29 & Diclofenac + Paracetamol + Chlorzoxazone & M03BB53 & & 1 & 0 \\
\hline \multicolumn{6}{|c|}{ N 04- Anti-Parkinson's drugs } \\
\hline 30 & Levodopa + Carbidopa & N04BA02 & $0.6 \mathrm{gm}$ & 1 & 0 \\
\hline \multicolumn{6}{|c|}{ N 05- Psycholeptics } \\
\hline 31 & $\begin{array}{l}\text { Chlordiazepoxide+ Clidinium bromide } \\
+ \text { Dicyclomine }\end{array}$ & N05BA & & 0 & 1 \\
\hline 32 & Chlordiazepoxide+ Clidinium bromide & N05BA & & 1 & 0 \\
\hline \multicolumn{6}{|c|}{ R 01- Nasal preparations } \\
\hline 33 & Cetirizine + Pseudoephedrine & R01B & & 1 & 1 \\
\hline \multicolumn{6}{|c|}{ R 03- Drugs for obstructive airway disease } \\
\hline 34 & Salmeterol + Fluticasone propionate & R03AK & & 2 & 1 \\
\hline 35 & Salbutamol + Budesonide & R03AK & & 1 & 0 \\
\hline 36 & $\begin{array}{l}\text { Cough syrup - Terbutaline+ Bromhexine } \\
\text { +Guaiphenesin+ Menthol }\end{array}$ & R03DA & & 3 & 7 \\
\hline \multicolumn{6}{|c|}{ R 05- Cough and cold preparations } \\
\hline 37 & $\begin{array}{l}\text { Cough syrup- Diphenhydramine +Ammo. } \\
\text { chloride+Sod. citrate + Menthol }\end{array}$ & R05FA02 & & 4 & 7 \\
\hline \multirow[t]{2}{*}{38} & Codeine+ Paracetamol + Chlorpheniramine & R05X & & 1 & 0 \\
\hline & & & & 90 & 69 \\
\hline & $\begin{array}{r}\text { xed Dose Combinations, WHO ATC - Worl } \\
\text { Clas }\end{array}$ & $\begin{array}{l}\text { Health Orga } \\
\text { ication }\end{array}$ & ation Anatc & 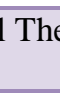 & mica \\
\hline
\end{tabular}

\section{DISCUSSION}

There is no difference in demographic characteristics in both the groups. Study included mainly the prescriptions for the patients in the age group of 16-60 years.
FDCs from antiinflammatory and antirheumatic products, vitamins, minerals, antianaemic preparations, drugs for acid related disorders, antibacterials for systemic use and cough and cold preparations prescribed by the both groups. antiinflammatory and antirheumatic products 
FDCs were prescribed significantly more by private practitioners in Pune. There is little evidence that any analgesic-antiinflammatory combination is better than its individual components alone. ${ }^{6}$ None of the analgesicantiinflammatory combinations has place in the WHO Model List of Essential Drugs. ${ }^{4}$

Cough syrups were prescribed significantly more by teaching hospital. Rational FDCs of GIT drugs, antibiotics and mineral supplements were prescribed more by teaching hospital as compared to non teaching private hospitals.

It is very difficult to correlate ADRs with FDCs prescription particularly when multiple drugs are prescribed in prescriptions. We had used literature data ${ }^{5}$, time course of appearance of adverse effects and period of drug administration for assigning ADR to particular FDCs. Out of 15 antibiotic FDCs prescribed by both the groups, 9 antibiotic FDCs were found be associated with development of ADRs. Antibiotic FDCs are made to achieve extended spectrum of action, if prescribed indiscriminately, definitely leads to adverse effects and resistance. Analgesic fixed dose combinations accounts for $55 \%$ ADRs.

Vitamins/minerals are not also free from ADRs as in this study, in 4 patients ADRs found to be associated with the use of vitamins and mineral FDCs. Significantly less number of rational mineral and vitamins FDCs were prescribed by private practitioner in Pune. Vitamins and minerals FDCs many times add only bulk to the prescriptions, also these preparations are inexpensive and in overdoses may be harmful. ${ }^{1}$ WHO Model List for Essential Drugs includes ascorbic acid, calcium, ferrous salts, folic acid, nicotinamide, pyridoxine, retinol, riboflavin, and thiamine among vitamins and minerals, as single drug formulation. The only fixed dose combination listed in WHO Essential Medicine List in vitamin/mineral category is of ferrous salt and folic acid. ${ }^{4}$

Polypharmacy and FDC prescriptions were less in SKNMC \& GH teaching hospital prescriptions as compared to non teaching private hospitals prescriptions. Kshirsagar et $\mathrm{al}^{2}$ in their study in Pune observed higher average number drugs per prescription as well as increased frequency of prescriptions of FDCs. Ansari et $\mathrm{al}^{7}$ in Allahabad District observed overprescription tendency more in private sector hospitals. Shewade et al ${ }^{1}$ in their study carried out in Pondicherry observed more average number of drugs per prescription, more FDCs prescription and less number of FDCs compliant WHO Essential Drug List in prescriptions of nonteaching private hospitals as compared to Government teaching hospital. Our observations are also in line with these studies.

CIMS $^{8}$ and DRUG TODAY ${ }^{9}$ indices of marketed drugs have listed various irrational FDC preparations in the class of antiinflammatory and antirheumatic products, vitamins, minerals, antianaemic preparations, drugs for acid related disorders and cough and cold preparations available in the Indian market. Kshirsagar et $\mathrm{al}^{2}$ in their study, evaluated prescription formulations listed in CIMS and observed that 50 irrational prescriptions of tonics and $64 \%$ FDCs were deemed unnecessary.

Pharmaceutical companies are producing more number of irrational FDCs as listed in indices of marketed drugs and using various tactics for prescriptions of these FDCs. CIMS lists more than 100 irrational drug combinations which are not approved in any other developed country but are being marketed in India. ${ }^{10}$ FDA can regulate this by not giving permission for manufacturing of new FDCs unless it is proved better than older drugs/ FDCs.

Rational use of medicine is one of the essential elements to be achieved to improve quality of health and medical care for the patients and the community. Prescription evaluation studies by students as well as researchers, frequent workshops on rational use of drugs for private practitioners will be useful for improving rational prescribing of drugs. ${ }^{2,10,11}$ Training in pharmacotherapeutics to fresh graduates may also help in improving rational prescription of drugs $\mathrm{s}^{2,10}$ as specially in the medical curriculum in India, medical students get training of pharmacotherapeutics in II MBBS phase. Selection of $\mathrm{P}$ drugs, rational drug use, use of rational drugs combinations should be included in the student's curriculum during their clinical training. ${ }^{10}$

\section{CONCLUSIONS}

More than $80 \%$ of prescribed FDCs are not in accordance with WHO Model List for Essential Drugs. As antiinflammatory and antirheumatic FDCs are liable for added ADRs, they should not be prescribed casually. Most of the anti-inflammatory and antirheumatic FDCs used are additive rather than synergistic. Vitamins/mineral supplement, antianaemia FDCs should be prescribed judiciously as they are not free from ADRs and also add to the increased budget for drugs. Polypharmacy is practiced more when more number of FDCs are prescribed. FDCs are prescribed in less number in teaching hospital as compared to non teaching private hospitals, probably because of stocking of drugs in hospital pharmacy as per Essential Medicine List. Critical reappraisal is required to weed out irrational FDCs from the market. Training of practitioners, repeated workshops on rational prescribing, re-training in pharmacotherapeutics may helpful in improving rational prescribing of drugs.

Funding: No funding sources

Competing interests: None declared

Ethical approval: The study was approved by the Institutional Ethics Committee of Smt. Kashibai Navale Medical College and Hospital, Narhe Ambegaon, Pune, India 


\section{REFERENCES}

1. Shewade DG, Pradhan SC. Auditing of prescriptions in a government teaching hospital and four retail medical stores in Pondicherry. Indian J Pharmacol 1998;30:408-10.

2. Kshirsagar MJ, Langade D, Patil S, Patki PS. Prescribing patterns among medical practitioners in Pune, India. Bull World Health Organ 1998;76:2715.

3. Kastury N, Singh S, Ansari KU. An audit of prescription for rational use of fixed dose drug combinations. Indian J Pharmacol 1999;31:367-9.

4. WHO Model list of Essential drugs 2011, 17th edition (March 2011). Available at http://www.who.int/medicines/publications/essential medicines/en/. Accessed 12 September 2012.

5. Tripathi KD. Essentials of Medical Pharmacology, 6th edition, Jaypee Brothers Medical Publishers (P) Ltd, New Delhi, 2008.
6. Beares WT. Analgesic combinations. In: Lasagna, editor. Combination drugs: Their uses and regulation. New York, Stration International Medical Book Corporation, 1975:52-72.

7. Ansari KU, Singh S, Pandey RC. Evaluation of doctors for rational drug therapy. Indian $\mathbf{J}$ Pharmacol 1998;30:43-46.

8. Current index of medical specialities (CIMS), JulyOct 2011 (update 3). Bangalore, India: CMP Medica India; 2011.

9. DRUG TODAY, July-Sept 2011 (volume 1 \& 2) Delhi, Lorina Publication (India) Inc., 2011.

10. Gautam CS, Aditya S. Irrational drug combinations: Need to sensitize undergraduates. Indian $\mathbf{J}$ Pharmacol 2006;38:169-70.

11. Rahman Z, Nazneen R, Begum M. Evaluation of prescribing pattern of the private practitioners by the undergraduate medical students. Bangladesh J Pharmacol 2009;4:73-5.

doi: 10.5455/2319-2003.ijbcp20130112

Cite this article as: Pillay A, Keche Y, Yegnanarayan R, Patil V, Patil G, Dangare R. Evaluation of prescribing patterns of teaching and non teaching hospitals by undergraduate medical students in Pune, India. Int J Basic Clin Pharmacol 2013;2:61-8. 